[Frontiers in Bioscience S2, 184-193, January 1, 2010]

\title{
Cancer stem cell and niche
}

\section{Hongmei Jiang ${ }^{1}$, Daotai Nie ${ }^{1}$}

${ }^{I}$ Department of Medical Microbiology, Immunology, and Cell Biology, Southern Illinois University School of Medicine and Simmons Cooper Cancer Institute, Springfield, IL

\section{TABLE OF CONTENTS}

1. Abstract

2. Introduction

3. Origin and identification of cancer stem cell

4. Role of CSCs in tumor progression

4.1. CSCs and cancer metastasis

4.2. CSCs and tumor angiogenesis

5. CSCs and their niche

6. Cellular signaling pathways regulating CSCs

6.1. Wnt pathway

6.2. Notch pathway

6.3. Sonic hedgehog homolog (Shh) pathways

7. CSCs in cancer therapy

8. Future direction

9. Acknowledgement

10. Reference

\section{ABSTRACT}

Recent research on cancer has generated a new model for cancer growth-cancer stem cell model. This model can explain the inefficiency of conventional therapy. Tumor tissue, like normal tissue, is continuously repopulated from pools of self-renewing stem cells growing in a "niche", which is made up of a specialized vascular bed of endothelial cells, associated cells of mesenchymal origin and extracellular matrix components. In this review, we will introduce the models of cancer development, the roles of stem cells in tumor progression, the components of niche which affects the cell fate of cancer stem cells (CSCs), their different regulatory factors, as well as the clinical implication of CSCs in cancer treatment.

\section{INTRODUCTION}

There are two different models explaining the cancer initiation. According to clonal evolution model, cancer is formed through the accumulation of genetic changes in cells and gradual selection of clones and each cell has the potential to be cancerous (Figure 1a). The failure to explain the inefficiency of the conventional therapy has given rise to another model-cancer stem cell model, which suggested that only a small proportion of the cells, which are called cancer stem cells, are responsible for the cancer initiation (Figure 1b) (1). This theory was first presented in the mid-19th century as the "embryonal rest" theory of cancer (2). About one century later, it was postulated that cancers arise from tissue stem cells (3). Dick and his 
Table 1. Cell surface phenotype of CSCs identified in human cancers

\begin{tabular}{|l|l|l|}
\hline Cancer & CSC phenotype & Reference \\
\hline AML & $\mathrm{CD} 34^{+} \mathrm{CD} 38^{-} \mathrm{CD} 90^{-}$ & $(4),(8)$ \\
\hline Breast cancer & $\mathrm{ESA}^{+} \mathrm{CD} 44^{+} \mathrm{CD} 24^{-\gamma^{-10} \mathrm{Lin}^{-}}$ & $(9)$ \\
\hline Brain cancer & $\mathrm{CD} 133^{+}$ & $(76)$ \\
\hline Colon cancer & $\mathrm{CD} 133^{+}, \mathrm{CD}_{4}{ }^{+} \mathrm{EpCam}^{+} \mathrm{CD} 166^{+}$ & $(77),(78)$ \\
\hline Osteosarcoma & $\mathrm{CD} 133^{+}$ & $(79)$ \\
\hline Pancreatic cancer & $\mathrm{CD} 44^{+} \mathrm{CD} 24^{+} \mathrm{ESA}^{+}$ & $(80)$ \\
\hline Prostate cancer & $\mathrm{CD} 44^{+}$alpha2beta $1^{+} \mathrm{CD} 133^{+}$ & $(81)$ \\
\hline
\end{tabular}

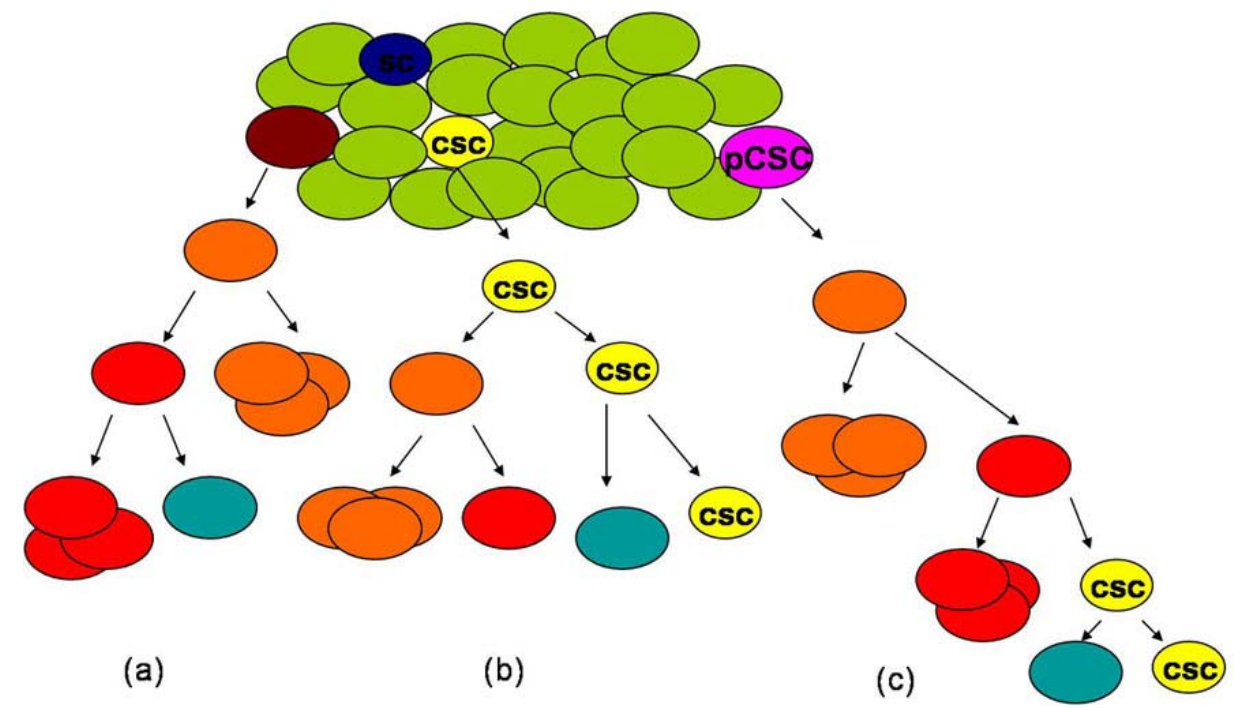

Figure 1. The models of tumor development: (a) clonal evolution model; (b) cancer stem cell model; (c) "pCSCs" integrated the two model. Green $=$ niche cells; blue = stem cell $(\mathrm{SC})$; yellow $=$ cancer stem cells $(\mathrm{CSCs})$; brown, orange, red, dark turquoise $=$ cell accumulating genetic alternation.

colleagues identified an AML-initiating cell by transplantation into severe combined immune-deficient (SCID) mice. The frequency of these leukemia-initiating cells in the peripheral blood of AML patients was one engraftment unit in 250,000 cells (4).

Recently, Gao et al. experimentally identified a new type of cancer cells, precancerous stem cells ('pCSCs'), which is considered as the precursor of CSCs. The pCSCs undergo multi-step mutations, and then can become CSCs (5). The identification of pCSCs in cancer integrates the two models (Figure 1c).

Stem cell function depends on the interaction between intrinsic genetic programs and extrinsic regulatory cues derived from a stem cell's microenvironment or 'niche'. The concept of the stem cell niche was initially proposed by Schofield in the context of the mammalian blood system (6). Niche cells provide a sheltering environment that protects stem cells from differentiation stimuli, apoptotic stimuli, and other stimuli that would challenge stem cell reserves. A functional niche can maintain the balance of stem cell quiescence and activity (7).

The cancer stem cell theory can shed light on cancer therapy. According to this theory, the treatment should target on the cancer stem cell instead of other cells in tumor.

\section{ORIGIN AND IDENTIFICATION OF CANCER STEM CELL}

The stem cells can be identified according to the surface proteins by flow cytometry. It was found that the leukemia-initiating cells that could engraft SCID mice to produce large numbers of colony-forming progenitors were CD34+CD38- (4) and CD90- (Thy-1- ) (8). Al-Hajj et al. identified and prospectively isolated tumorigenic cells from a human solid tumor (breast cancer) as CD44+CD24/lowLineage- in eight of nine patients (9). Virginia Tirino et al. (2008), have identified, for the first time, CD133+ cells within osteosarcoma cell lines, showing many features of cancer stem cells (10). In addition, researchers have identified a CSC population in other solid tumors, such as brain, prostate, colon and pancreatic cancers. The cell surface phenotypes of CSC populations from these human tumors are described in Table 1.

\section{ROLE OF CSCs IN TUMOR PROGRESSION}

The cancer stem cell model has elucidated the role of CSCs in tumor formation. Besides initiation of tumor, CSCs play an important role in tumor progression, such as metastasis and angiogenesis.

\subsection{CSCs and cancer metastasis}

Metastasis is one of the most ominous properties of malignant cancer (11). Metastasis is a sequential, multi- 
step process that requires cancer cells to escape from the primary tumor, intravasate into the circulation or lymphatic system, migrate through the body, adhere at a secondary site, extravasate from the circulation and into the secondary tissue, form micrometastases, develop a blood supply, and finally form macroscopic, clinically relevant metastases $(12,13)$. Metastasis is known to be an inefficient process. It was found that only $\sim 2 \%$ of disseminated cells were able to form micrometastases, and only $\sim 0.02 \%$ of cells were able to develop into vascularized macrometastases, although almost $90 \%$ of the cells could successfully get through the early steps in the metastasis process(14).

One explanation of this inefficiency is the need for the metastatic cells to find favorite sites to survive or proliferate. Stepen Paget first proposed the "seed and soil" theory in 1889 . He predicted that cancer cells (the "seed") can survive and proliferate only in secondary sites (the "soil") that produce growth factors appropriate to the type of cell (15). Application of the CSC hypothesis to metastasis therefore suggests that this rare subset of cells within a primary tumor that are capable of forming metastases in distant sites may in fact be CSCs. This is supported by the observation that metastatic cells and stem cells share a number of key properties, including an unlimited capacity for self-renewal; the requirement for a specific 'niche' or microenvironment to grow (and, juxtapositional with that, a self-protective ability to grow in harsh environments); use of the SDF-1/CXCR4 axis for migration; enhanced resistance to apoptosis; and an increased capacity for drug resistance (16). Hermann and colleagues used human pancreatic cancer as a model system to study the relationship between CSCs and metastasis. They found both of $\mathrm{CD}_{133^{+} / \mathrm{CXCR}^{-} \text {and }}$ $\mathrm{CD} 33^{+} / \mathrm{CXCR}^{+}$cell lines are capable of forming tumors after orthotopic injection in the pancreas of immunodeficient "nude" mice, while only the $\mathrm{CD} 133^{+} / \mathrm{CXCR}^{+}$cell line was able to form spontaneous metastasis, at least in the short/medium term (17).

In traditional cancer models, metastases are considered to originate from monoclonal expansions of very specific, individual tumor subclones, which can accumulate further mutations and become substantially different from primary tumors (18). In contrast to this model, striking similarities over a wide range of parameters, including tissue morphology $(19,20)$, repertoire of somatic genetic mutations (21-23), expression of tumor-suppressor and immunomodulatory proteins (24), expression of epigenetically controlled genes (25), and overall transcriptional profile as defined by gene expression arrays (26-28) were revealed, when comparing paired samples of primary tumors and autologous lymph node and/or distant-site metastases. However, in CSC model we can assume that, in each individual tumor, the differentiation pattern is controlled by its specific repertoire of genetic mutations. If two lesions share identical genetic backgrounds and similar genetic abnormalities, they will also undergo similar differentiation programs and display similar patterns of intratumor heterogeneity in the expression of differentiation antigens $(19,20)$.

\subsection{CSCs and tumor angiogenesis}

Acquisition of angiogenic ability by tumor cells is a hallmark of carcinogenesis and is essential for tumor growth. Vascular endothelial growth factor (VEGF) is an important angiogenic factor, which is mainly responsible for the physiological process involving the growth of new blood vessels from preexisting vessels or the fundamental step in the transition of tumor from a dormant state to malignant one (29).

Some studies indicate that CSCs contribute to tumor angiogenesis. Bao, et al. (2006) examined the potential of stem cell-like glioma cells (SCLGC) to support tumor angiogenesis. They found that tumor derived from SCLGC were morphologically distinguishable from nonSCLGC tumor population by widespread tumor angiogenesis, necrosis, and hemorrhage. In comparison with matched non-SCLGC populations, SCLGC consistently secreted markedly elevated levels of vascular endothelial growth factor (VEGF), which were further induced by hypoxia. In an in vitro model of angiogenesis, SCLGC-conditioned medium significantly increased endothelial cell migration and tube formation compared with non-SCLGC tumor cell-conditioned medium (30). In breast cancer, the stem-cell subpopulation may be more adept at promoting angiogenesis than its nonstem-cell counterpart (31). Additional research showed that the stem cell factor can activate microvascular endothelial cells in vivo and induce a potent angiogenic response in vivo (32). All of these studies confirmed the role of CSCs in promoting tumor angiogenesis.

\section{CSCS AND THEIR NICHE}

Since the existence of the stem cell niche in vivo was first confirmed in the Drosophila GSC (germ-line stem cells) (33), much progress has been made in identifying stem cell niches in various mammal tissues, including nerves, hair follicles, intestines, teeth, and bone marrow (34-39).

The composition of the niche is very complex, and varied in specific tissues. In this review, we will focus on the several components of tumor stroma and extracellular matrix (ECM).

Fibroblasts are the main cellular component of tumor stroma comprising an integral component of the tumor. Cancer-associated fibroblasts (CAFs) can be distinguished from normal fibroblasts by their perpetual activation, expression of alpha-smooth muscle actin, and are usually surrounded by dense accumulation of fibrillar collagens (40, 41). Tlsty and colleagues determined that CAFs send signals that either induce abnormal epithelial growth or enhance the progression of nontumorigenic cells to tumorigenic state (40). CAFs have been shown to assist in proliferation and progression of cancer through the production of growth factors and chemotactic factors, angiogenic factors, and matrix metalloproteinases (MMPs) (41).

The innate immune cells are also important components of tumor stroma. Tumor-associated macrophages (TAMs) prefer to attach to and retain in areas 


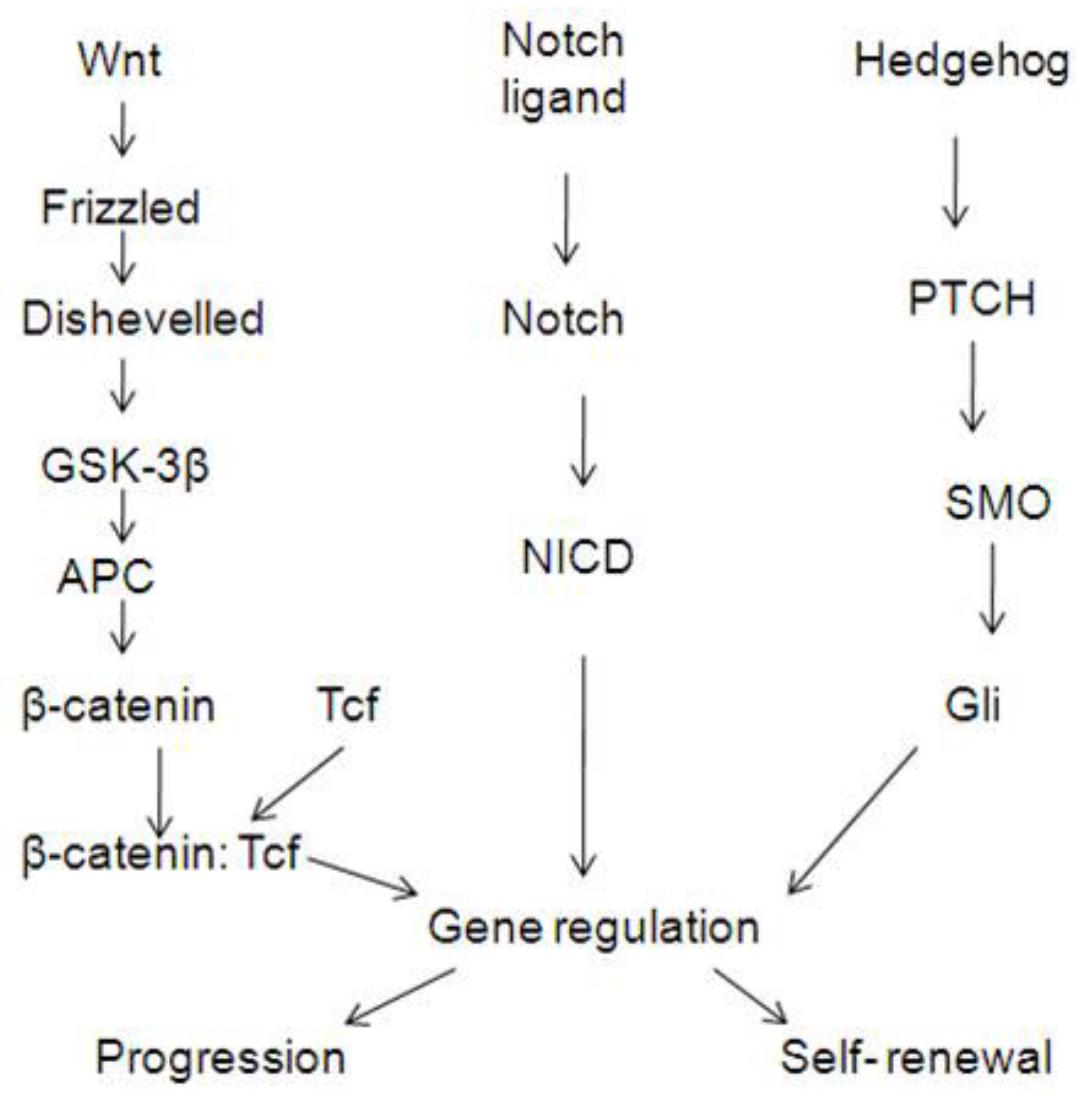

Figure 2. The potential responses of CSC to different signal pathways.

of necrosis and hypoxia where their phenotypes are altered and Hypoxia-induced transcription factors (HIF) are upregulated. TAMs have been found to enhance angiogenesis by releasing a number of factors including VEGF, HGF (hepatocyte growth factor), matrix metalloproteinases 2 (MMP2) and IL-8 (Interleukin 8) (41, 42). There are some other studies reported that adaptive immune cells, e.g., B and T lymphocytes, may inhibit later stages of cancer development. This is known as "immunesurveillance theory" (40).

Hypoxic environment in tumors, as a result of rapid cell division and aberrant blood vessel formation, can contribute to cancer progression by activating adaptive transcriptional programs that promote cell survival, motility, and tumor angiogenesis (43). HIF (hypoxiainducible factor) can mediate some effects of hypoxia on stem cell functions via multiple mechanisms. Takahashi and Yamanaka found that directed expression of four transgenes, KLF4, Sox2, Oct4, and c-Myc can convert normal murine fibroblast into cells closely resembling ES cells (44). Among the four factors, Oct4 and c-Myc are directly activated by HIF-2alpha via different mechanism (43). Notch activity regulated by HIF may also contribute to cancer stem cell formation (43). Besides, HIF target proteins regulating other stem cell functions, such as human gene encoding the ABC (ATP-binding Cassette) glycoprotein transporter MDR1, Bcrp/ABCG2, and the gene encoding the enzymatic component of human telomerase (hTERT) is induced by hypoxia in a HIFdependent manner (45-47).

The composition of ECM includes fibrillar proteins, glycoproteins, proteoglycans, cytokines, and growth factors (48). The ECM provides both the structural support and contextual information for cells to respond to a given set of stimuli (49). It remains to be investigated, however, how CSCs interact with the constituents of tumor stroma.

\section{CELLULAR SIGNALING PATHWAYS REGULATIONG CSCs}

The niche regulates the balance of stem cell between self-renewal and differentiation by signaling pathways. We will discuss the developmental pathway, such as Wnt, Notch and Shh (Figure 2).

\subsection{Wnt pathway}

The Wnts comprise a large family of protein ligands that affect diverse processes such as embryonic induction, cell polarity generation, and the cell fate decision (50). There are two types of Wnt receptors, one is Frizzled family of seven-pass transmembrane proteins, and another is a subset of the low-density lipoprotein receptor-related protein (or the LRP) family(51). In the absence of Wnt protein, beta-catenin, which is a downstream effector of 
Wnt pathway, is phosphorylated by a multiple protein complexes, including the kinases GSK3beta (glycogen synthase kinase-3beta) and CK1 (casein kinase 1) and the scaffolding proteins APC, Axin1 and Axin2, for ubiquitination and proteolytic degradation. After binding to the Wnt ligands, the Frizzled and LRP receptors destruct the inhibitory protein complex and stabilize the betacatenin. Eventually, the accumulated intracellular betacatenin leads to its nuclear translocation, where it binds to the Tcf/Lef transcription factor family to regulate the expression of a broad range of target genes. Alternately, Wnts also signal through tyrosine kinase receptors, particularly the ROR and RYK receptors (52).

The contribution of Wnt signaling pathway to stem cell self-renewal is supported by several studies on various stem cells. To identify the function of Wnt in hematopoietic stem cells (HSCs), Reya et al. transduced downstream components of the Wnt signaling pathway into highly purified mouse bone marrow HSCs and analyzed their effects in vitro and in vivo assay. They found that overexpression of activated beta-catenin of HSCs increased the number of HSCs and ectopic expression of Axin, led to inhibition of HSCs proliferation and increased cell death of HSCs (51). Yi F et al. found that Tcf-3, a DNA-binding effector of Wnt signaling can reduce several promoters of self-renewal genes, such as Nanog, Tcl1, Tbx3, and Esrrb (53). In neural system, M. Yashar et al. uncovered the role of Wnt signal in stem cell renewal in the brain (54).

Aberrant Wnt signaling may disrupt the homeostasis between self-renewal and proliferation of stem cells and then cause cancer. Mutations of beta-catenin including the changes of specific serine and threonine residues, and amino acids adjacent to them, which are essential for the targeted degradation of beta-catenin, are found in various human cancers (55). Gat et al. indicated aberrant beta-catenin activation in epidermal stem cells leading to hair tumors (56). Reya et al. has showed that the mice with conditional deletion of beta-catenin impaired the development of Bcr-Abl-induced chronic myeloid leukemia (CML) (57).

In addition, the mutations of beta-catenin phosphorylation complex, including GSK3beta, APC, Axin and so on, can cause cancers. Xie et al. found mutations of GSK3beta were frequently found in myeloid blast-crisis leukemia stem cells from CML patients (58). APC mutations are frequently found in FAP (Familial adenomatous polyposis) and colorectal cancers, but are quite rare in other cancers (55). Axin mutations are found in hepatocarcinomas with intact genes for beta-catenin and APC (55). Malanchi et al. have identified that Wnt/betacatenin signaling is essential to maintain cancer stem cell phenotypes within a population of cells isolated from early epidermal tumors (59). In their study, they found that deletion of beta-catenin gene resulted in the loss of CSCs and caused tumor regression and that increased betacatenin signaling is involved in the malignant human squamous cell carcinoma (59). The findings, taken together, suggest an important role for Wnt signaling in the self-renewal of cancer stem cells.

\subsection{Notch pathway}

The Notch signaling pathway can regulate embryonic development, maintenance of homeostasis in adults. With other signaling pathways, such as Wnt and hedgehog, Notch pathway can regulate stem cell selfrenewal. In mammals, four Notch receptors (Notch1Notch-4) and five single-pass transmembrane Notch ligands (Delta-like 1, 2, 3, Jagged1, 2) have been identified (60). After glycosylation of the receptors precursor, the receptors are cleaved into Notch extracellular domain (NECD) and intracellular domain (NICD) by protease. Upon ligand binding, Notch undergoes two further proteolytic cleavages, which lead to the release of NICD, and translocation of librated NICD into nucleus, where it forms a ternary complex with the DNA-binding CSL (CBF1/suppressor of Hairless/ Lag1) transcription factors as well as Mastermind (Mam), leading to the recruiting of more transcription factors activating target gene expression (61). The influence of Notch signaling on the HSC and melanocyte generation, CNS and vascular development, embryogenesis, as well as homeostatic balance of immune system, intestinal mucosa, skeleton, skin and hair systems has been demonstrated (60). Since 1991 when mammalian Notch1 was first identified as part of the translocation $t(7 ; 9)$ in a subset of human T-cell acute lymphoblastic leukemias (T-ALL), the aberrant Notch activation have been found in many cancers, such as mammary tumor, lung cancer, neuroblastomas, skin cancer, cervical cancer and prostate cancer $(62,63)$.

\subsection{Sonic hedgehog homolog (Shh) pathways}

The hedgehog $(\mathrm{Hh})$ signaling pathway is one of the most fundamental signal pathways contributing to embryonic development. Sonic hedgehog is one of three proteins in mammalian hedgehog family (the other two are desert hedgehog and Indian hedgehog, respectively). The receptor for Shh is the product of the tumor suppressor gene, PTCH. Then, Smoothened (SMO) protein activates the expression of downstream target genes, which include $g l i$, PTCH and members of the TGF-beta family. Besides a key role in regulation of vertebrate organogenesis, like in the growth of digits on limbs and organization of the brain, Shh signaling pathway is also involved in the stem cell regulation (64). In skin, for instance, the Shh pathway plays an important role in the maintenance of skin stem cells, as well as the modulation of hair follicles and sebaceous gland development (64). It also maintains the self-renewal potential of HSCs and the expansions of progenitor cells (65). Likewise, the mutation of Shh pathway is associated with various types of cancers, such as multiple myeloma and prostate cancer (66). Moreover, the basal cell carcinoma, medulloblastoma, rhabdomyosarcoma and other types of human tumors are associated with abnormalities of Shh signaling, such as the mutated activation of SMO which is a proto-oncogene and the arrested activation of tumor suppressor PTCH (64).

Iwatsuki et al found that Shh and components of Wnt/beta-catenin signaling pathway were expressed together during fungiform papilla formation in mice. They determined that activation of $\mathrm{Wnt} /$ beta-catenin signaling 
up-regulated Shh expression by examining embryonic mouse tongues in culture. They also observed that blocking Shh signaling in cultured tongue explants enhanced papillae formation and was accompanied by an upregulation of $\mathrm{Wnt} /$ beta-catenin signaling, indicating that the Shh inhibits the Wnt/beta-catenin pathway (67).

Further studies are required to untangle the various cellular signaling pathways involved in maintenance of adult stem cells and CSCs.

\section{CSCS IN THERAPHY}

Current methods of treatment are usually characterized by poor selectivity, i.e. the drug acts not only on tumor cells but also on normal cells. This is one of the causes of ineffectiveness and serious adverse effects of such treatment. If the CSC theory proves to be true, then treatment should be aimed at selective elimination of CSCs from the body and not the cells that form the main mass of the tumor (1). Another factor we must take into account is the importance of targeting tumor cell niches while sparing normal stem cell niches. Tumor stem cells may be extremely well protected from apoptosis by survival factors provided by the stromal cells in the niche (68).

Increased resistance of CSCs to chemotherapy and radiotherapy is confirmed by several studies. Guzman et al. have shown that leukemia stem cells are more resistant to chemotherapy than the more differentiated myeloblastic cells that constitute the vast majority of cells in leukemia (69). Similarly, Matsui et al. have shown that myeloma stem cells are resistant to many therapies being used to treat myeloma (70). In breast cancer model systems, CD $44^{+} / \mathrm{CD} 24^{-/ \text {low }} \mathrm{CSC}$ from MCF-7 and MDAMB-231 cancer cell lines were isolated and subjected to a single dose of radiation. The CSCs were observed to be more radioresistant, had fewer or no double stranded DNA breaks (or they were quickly repaired), and had a $50 \%$ lower dose-dependent formation of reactive oxygen species (ROS) in response to the radiation. In addition, the increase in the CSC population was associated with the activation of Notch-1 (important in specifying cell fate during development), so it is possible that CSCs activate this developmental pathway in response to radiation $(71,72)$. The mechanism of CSCs resistance to apoptosis may include cell cycle kinetic, DNA replication and repair mechanism, asynchronous DNA synthesis, antiapoptotic proteins and transporter proteins (73).

Targeted therapy has been involved, but it seems that some CSCs can also be escaped from targeting. Michor et al. suggest that although imatinib may target differentiated and progenitor CML cells, it does not eliminate CML stem cells (74). Treatment of CD $133^{+}$CSCs derived from human GBMs (glioblastomas) with bone morphogenic proteins (BMP) reduced cell proliferation in vitro and induced differentiation into astrocytes. The BMP treatment reduced the size and invasive capacity of the tumors engrafted into mice and prolonged their overall survival. It seems that some CSCs escape the differentiation effects of BMP treatment, because some mice still developed tumors and died 3 months after BMP treatment (75).

The cancer stem cell model suggests that it may be necessary to eradicate cancer stem cell. The goal is to kill these cancer stem cells selectively while sparing normal stem cells. However, it is a challenge since cancer stem cells and normal stem cells share many pathways.

\section{FUTURE DIRECTIONS}

Although great strides have made in CSCs research, the knowledge about these tumor-initiating cells is still limited. To better understand the CSCs, the origin of the CSCs should be elucidated. Do they arise from normal stem cells or the progenitor cells? Regarding the role of CSCs niche in tumor progression, it is essential to know the components of the niche, and how they induce tumor progression. Hypoxia microenvironment is one of the most potent stimuli of VEGF, so the response of CSCs toward hypoxia should be a focus of further investigations. Further studies are needed on how the signaling pathways mediate stem cell self-renewal and differentiation. Finally, the most challenging task is perhaps to define the difference between CSCs and normal stem cells, and to identify the specific markers of CSCs in a specific type of tumor so that this knowledge can be used for cancer therapy.

\section{ACKNOWLEDGEMENT}

I would like to thank Dr. Kounosuke Watabe for comments and suggestion.

\section{REFERENCE}

1. Gil, J., A. Stembalska, K. A. Pesz \& M. M. Sasiadek: Cancer stem cells: the theory and perspectives in cancer therapy. J Appl Genet, 49, 193-9 (2008)

2. Sell, S.: Stem cell origin of cancer and differentiation therapy. Crit Rev Oncol Hematol, 51, 1-28 (2004)

3. Till, J. E. \& C. E. Mc: A direct measurement of the radiation sensitivity of normal mouse bone marrow cells. Radiat Res, 14, 213-22 (1961)

4. Lapidot, T., C. Sirard, J. Vormoor, B. Murdoch, T. Hoang, J. Caceres-Cortes, M. Minden, B. Paterson, M. A. Caligiuri \& J. E. Dick: A cell initiating human acute myeloid leukaemia after transplantation into SCID mice. Nature, 367, 645-8 (1994)

5. Gao, J. X.: Cancer stem cells: the lessons from precancerous stem cells. J Cell Mol Med, 12, 67-96 (2008)

6. Schofield, R.: The relationship between the spleen colony-forming cell and the haemopoietic stem cell. Blood Cells, 4, 7-25 (1978)

7. Moore, K. A. \& I. R. Lemischka: Stem cells and their niches. Science, 311, 1880-5 (2006) 
8. Blair, A., D. E. Hogge, L. E. Ailles, P. M. Lansdorp \& H. J. Sutherland: Lack of expression of Thy-1 (CD90) on acute myeloid leukemia cells with long-term proliferative ability in vitro and in vivo. Blood, 89, 3104-12 (1997)

9. Al-Hajj, M., M. S. Wicha, A. Benito-Hernandez, S. J. Morrison \& M. F. Clarke: Prospective identification of tumorigenic breast cancer cells. Proc Natl Acad Sci U S A, $100,3983-8(2003)$

10. Tirino, V., V. Desiderio, R. d'Aquino, F. De Francesco, G. Pirozzi, A. Graziano, U. Galderisi, C. Cavaliere, A. De Rosa, G. Papaccio \& A. Giordano: Detection and characterization of CD133+ cancer stem cells in human solid tumours. PLoS ONE, 3, e3469 (2008)

11. Dalerba, P. \& M. F. Clarke: Cancer stem cells and tumor metastasis: first steps into uncharted territory. Cell Stem Cell, 1, 241-2 (2007)

12. Chambers, A. F., A. C. Groom \& I. C. MacDonald: Dissemination and growth of cancer cells in metastatic sites. Nat Rev Cancer, 2, 563-72 (2002)

13. Pantel, K. \& R. H. Brakenhoff: Dissecting the metastatic cascade. Nat Rev Cancer, 4, 448-56 (2004)

14. Luzzi, K. J., I. C. MacDonald, E. E. Schmidt, N. Kerkvliet, V. L. Morris, A. F. Chambers \& A. C. Groom: Multistep nature of metastatic inefficiency: dormancy of solitary cells after successful extravasation and limited survival of early micrometastases. Am J Pathol, 153, 86573 (1998)

15. Paget, S.: The distribution of secondary growths in cancer of the breast. 1889. Cancer Metastasis Rev, 8, 98101 (1989)

16. Croker, A. K. \& A. L. Allan: Cancer stem cells: implications for the progression and treatment of metastatic disease. J Cell Mol Med, 12, 374-90 (2008)

17. Hermann, P. C., S. L. Huber, T. Herrler, A. Aicher, J. W. Ellwart, M. Guba, C. J. Bruns \& C. Heeschen: Distinct populations of cancer stem cells determine tumor growth and metastatic activity in human pancreatic cancer. Cell Stem Cell, 1, 313-23 (2007)

18. Dalerba, P., R. W. Cho \& M. F. Clarke: Cancer stem cells: models and concepts. Annu Rev Med, 58, 267-84 (2007)

19. Brabletz, T., A. Jung, S. Spaderna, F. Hlubek \& T. Kirchner: Opinion: migrating cancer stem cells - an integrated concept of malignant tumour progression. Nat Rev Cancer, 5, 744-9 (2005)

20. Brabletz, T., A. Jung, S. Reu, M. Porzner, F. Hlubek, L. A. Kunz-Schughart, R. Knuechel \& T. Kirchner: Variable beta-catenin expression in colorectal cancers indicates tumor progression driven by the tumor environment. Proc Natl Acad Sci U S A, 98, 10356-61 (2001)
21. Losi, L., J. Benhattar \& J. Costa: Stability of K-ras mutations throughout the natural history of human colorectal cancer. Eur J Cancer, 28A, 1115-20 (1992)

22. Khan, Z. A., S. K. Jonas, N. Le-Marer, H. Patel, R. Q. Wharton, A. Tarragona, A. Ivison \& T. G. Allen-Mersh: P53 mutations in primary and metastatic tumors and circulating tumor cells from colorectal carcinoma patients. Clin Cancer Res, 6, 3499-504 (2000)

23. Zauber, P., M. Sabbath-Solitare, S. P. Marotta \& D. T. Bishop: Molecular changes in the Ki-ras and APC genes in primary colorectal carcinoma and synchronous metastases compared with the findings in accompanying adenomas. Mol Pathol, 56, 137-40 (2003)

24. Menon, A. G., R. A. Tollenaar, C. J. van de Velde, H. Putter, C. M. Janssen-van Rhijn, R. Keijzer, G. J. Fleuren \& P. J. Kuppen: p53 and HLA class-I expression are not down-regulated in colorectal cancer liver metastases. Clin Exp Metastasis, 21, 79-85 (2004)

25. Dalerba, P., A. Ricci, V. Russo, D. Rigatti, M. R. Nicotra, M. Mottolese, C. Bordignon, P. G. Natali \& C. Traversari: High homogeneity of MAGE, BAGE, GAGE, tyrosinase and Melan-A/MART-1 gene expression in clusters of multiple simultaneous metastases of human melanoma: implications for protocol design of therapeutic antigen-specific vaccination strategies. Int J Cancer, 77, 200-4 (1998)

26. D'Arrigo, A., C. Belluco, A. Ambrosi, M. Digito, G. Esposito, A. Bertola, M. Fabris, V. Nofrate, E. Mammano, A. Leon, D. Nitti \& M. Lise: Metastatic transcriptional pattern revealed by gene expression profiling in primary colorectal carcinoma. Int J Cancer, 115, 256-62 (2005)

27. Weigelt, B., A. M. Glas, L. F. Wessels, A. T. Witteveen, J. L. Peterse \& L. J. van't Veer: Gene expression profiles of primary breast tumors maintained in distant metastases. Proc Natl Acad Sci US A, 100, 15901-5 (2003)

28. Weigelt, B., J. L. Peterse \& L. J. van 't Veer: Breast cancer metastasis: markers and models. Nat Rev Cancer, 5, 591-602 (2005)

29. Si, Z. C. \& J. Liu: What "helps" tumors evade vascular targeting treatment? Chin Med J (Engl), 121, 844-9 (2008)

30. Bao, S., Q. Wu, S. Sathornsumetee, Y. Hao, Z. Li, A. B. Hjelmeland, Q. Shi, R. E. McLendon, D. D. Bigner \& J. N. Rich: Stem cell-like glioma cells promote tumor angiogenesis through vascular endothelial growth factor. Cancer Res, 66, 7843-8 (2006)

31. Ponti, D., A. Costa, N. Zaffaroni, G. Pratesi, G. Petrangolini, D. Coradini, S. Pilotti, M. A. Pierotti \& M. G. Daidone: Isolation and in vitro propagation of tumorigenic breast cancer cells with stem/progenitor cell properties. Cancer Res, 65, 5506-11 (2005)

32. Sun, L., A. M. Hui, Q. Su, A. Vortmeyer, Y. Kotliarov, S. Pastorino, A. Passaniti, J. Menon, J. Walling, R. Bailey, 
M. Rosenblum, T. Mikkelsen \& H. A. Fine: Neuronal and glioma-derived stem cell factor induces angiogenesis within the brain. Cancer Cell, 9, 287-300 (2006)

33. Cox, D. N., A. Chao, J. Baker, L. Chang, D. Qiao \& H. Lin: A novel class of evolutionarily conserved genes defined by piwi are essential for stem cell self-renewal. Genes Dev, 12, 3715-27 (1998)

34. Tumbar, T., G. Guasch, V. Greco, C. Blanpain, W. E. Lowry, M. Rendl \& E. Fuchs: Defining the epithelial stem cell niche in skin. Science, 303, 359-63 (2004)

35. Yen, T. H. \& N. A. Wright: The gastrointestinal tract stem cell niche. Stem Cell Rev, 2, 203-12 (2006)

36. Conover, J. C. \& R. Q. Notti: The neural stem cell niche. Cell Tissue Res, 331, 211-24 (2008)

37. Doetsch, F.: A niche for adult neural stem cells. Curr Opin Genet Dev, 13, 543-50 (2003)

38. Ohshima, H., N. Nakasone, E. Hashimoto, H. Sakai, K. Nakakura-Ohshima \& H. Harada: The eternal tooth germ is formed at the apical end of continuously growing teeth. Arch Oral Biol, 50, 153-7 (2005)

39. Wilson, A. \& A. Trumpp: Bone-marrow haematopoietic-stem-cell niches. Nat Rev Immunol, 6, 93-106 (2006)

40. T1sty, T. D. \& L. M. Coussens: Tumor stroma and regulation of cancer development. Annu Rev Pathol, 1, 119-50 (2006)

41. Li, H., X. Fan \& J. Houghton: Tumor microenvironment: the role of the tumor stroma in cancer. J Cell Biochem, 101, 805-15 (2007)

42. DeNardo, D. G., M. Johansson \& L. M. Coussens: Immune cells as mediators of solid tumor metastasis. Cancer Metastasis Rev, 27, 11-8 (2008)

43. Keith, B. \& M. C. Simon: Hypoxia-inducible factors, stem cells, and cancer. Cell, 129, 465-72 (2007)

44. Takahashi, K. \& S. Yamanaka: Induction of pluripotent stem cells from mouse embryonic and adult fibroblast cultures by defined factors. Cell, 126, 663-76 (2006)

45. Comerford, K. M., T. J. Wallace, J. Karhausen, N. A. Louis, M. C. Montalto \& S. P. Colgan: Hypoxiainducible factor-1-dependent regulation of the multidrug resistance (MDR1) gene. Cancer Res, 62, 3387-94 (2002)

46. Krishnamurthy, P., D. D. Ross, T. Nakanishi, K. Bailey-Dell, S. Zhou, K. E. Mercer, B. Sarkadi, B. P. Sorrentino \& J. D. Schuetz: The stem cell marker Bcrp/ABCG2 enhances hypoxic cell survival through interactions with heme. J Biol Chem, 279, 24218-25 (2004)

47. Nishi, H., T. Nakada, S. Kyo, M. Inoue, J. W. Shay \& K. Isaka: Hypoxia-inducible factor 1 mediates upregulation of telomerase (hTERT). Mol Cell Biol, 24, 6076-83 (2004)

48. Aumailley, M. \& B. Gayraud: Structure and biological activity of the extracellular matrix. $J \mathrm{Mol} \mathrm{Med,} \mathrm{76,} \mathrm{253-65}$ (1998)

49. Howe, A., A. E. Aplin, S. K. Alahari \& R. L. Juliano: Integrin signaling and cell growth control. Curr Opin Cell Biol, 10, 220-31 (1998)

50. Logan, C. Y. \& R. Nusse: The Wnt signaling pathway in development and disease. Annu Rev Cell Dev Biol, 20, 781-810 (2004)

51. Reya, T.: Regulation of hematopoietic stem cell selfrenewal. Recent Prog Horm Res, 58, 283-95 (2003)

52. Nusse, R.: Wnt signaling and stem cell control. Cell Res, 18, 523-7 (2008)

53. Yi, F., L. Pereira \& B. J. Merrill: Tcf3 functions as a steady-state limiter of transcriptional programs of mouse embryonic stem cell self-renewal. Stem Cells, 26, 1951-60 (2008)

54. Kalani, M. Y., S. H. Cheshier, B. J. Cord, S. R. Bababeygy, H. Vogel, I. L. Weissman, T. D. Palmer \& R. Nusse: Wnt-mediated self-renewal of neural stem/progenitor cells. Proc Natl Acad Sci U S A, 105, 16970-5 (2008)

55. Kikuchi, A.: Tumor formation by genetic mutations in the components of the Wnt signaling pathway. Cancer Sci, 94, 225-9 (2003)

56. Gat, U., R. DasGupta, L. Degenstein \& E. Fuchs: De Novo hair follicle morphogenesis and hair tumors in mice expressing a truncated beta-catenin in skin. Cell, 95, 60514 (1998)

57. Zhao, C., J. Blum, A. Chen, H. Y. Kwon, S. H. Jung, J. M. Cook, A. Lagoo \& T. Reya: Loss of beta-catenin impairs the renewal of normal and CML stem cells in vivo. Cancer Cell, 12, 528-41 (2007)

58. Xie, T. \& L. Li: Stem cells and their niche: an inseparable relationship. Development, 134, 2001-6 (2007)

59. Malanchi, I., H. Peinado, D. Kassen, T. Hussenet, D. Metzger, P. Chambon, M. Huber, D. Hohl, A. Cano, W. Birchmeier \& J. Huelsken: Cutaneous cancer stem cell maintenance is dependent on beta-catenin signalling. Nature, 452, 650-3 (2008)

60. Chiba, S.: Notch signaling in stem cell systems. Stem Cells, 24, 2437-47 (2006) 
61. Roca, C. \& R. H. Adams: Regulation of vascular morphogenesis by Notch signaling. Genes Dev, 21, 2511-24 (2007)

62. Allenspach, E. J., I. Maillard, J. C. Aster \& W. S. Pear: Notch signaling in cancer. Cancer Biol Ther, 1, 466-76 (2002)

63. Ellisen, L. W., J. Bird, D. C. West, A. L. Soreng, T. C. Reynolds, S. D. Smith \& J. Sklar: TAN-1, the human homolog of the Drosophila notch gene, is broken by chromosomal translocations in T lymphoblastic neoplasms. Cell, 66, 649-61 (1991)

64. Athar, M., X. Tang, J. L. Lee, L. Kopelovich \& A. L. Kim: Hedgehog signalling in skin development and cancer. Exp Dermatol, 15, 667-77 (2006)

65. Lobo, N. A., Y. Shimono, D. Qian \& M. F. Clarke: The biology of cancer stem cells. Annu Rev Cell Dev Biol, 23, 67599 (2007)

66. Anton Aparicio, L. M., R. Garcia Campelo, J. Cassinello Espinosa, M. Valladares Ayerbes, M. Reboredo Lopez, S. Diaz Prado \& G. Aparicio Gallego: Prostate cancer and Hedgehog signalling pathway. Clin Transl Oncol, 9, 420-8 (2007)

67. Iwatsuki, K., H. X. Liu, A. Gronder, M. A. Singer, T. F. Lane, R. Grosschedl, C. M. Mistretta \& R. F. Margolskee: Wnt signaling interacts with Shh to regulate taste papilla development. Proc Natl Acad Sci U S A, 104, 2253-8 (2007)

68. Baguley, B. C.: Tumor stem cell niches: a new functional framework for the action of anticancer drugs. Recent Patents Anticancer Drug Discov, 1, 121-7 (2006)

69. Guzman, M. L., C. F. Swiderski, D. S. Howard, B. A. Grimes, R. M. Rossi, S. J. Szilvassy \& C. T. Jordan: Preferential induction of apoptosis for primary human leukemic stem cells. Proc Natl Acad Sci U S A, 99, 16220-5 (2002)

70. Jones, R. J., W. H. Matsui \& B. D. Smith: Cancer stem cells: are we missing the target? J Natl Cancer Inst, 96, 583-5 (2004)

71. Politi, K., N. Feirt \& J. Kitajewski: Notch in mammary gland development and breast cancer. Semin Cancer Biol, 14, 341-7 (2004)

72. Phillips, T. M., W. H. McBride \& F. Pajonk: The response of CD24(-/low)/CD44+ breast cancer-initiating cells to radiation. J Natl Cancer Inst, 98, 1777-85 (2006)

73. Wicha, M. S., S. Liu \& G. Dontu: Cancer stem cells: an old idea--a paradigm shift. Cancer Res, 66, 1883-90; discussion 1895-6 (2006)

74. Michor, F., T. P. Hughes, Y. Iwasa, S. Branford, N. P. Shah, C. L. Sawyers \& M. A. Nowak: Dynamics of chronic myeloid leukaemia. Nature, 435, 1267-70 (2005)
75. Sakariassen, P. O., H. Immervoll \& M. Chekenya: Cancer stem cells as mediators of treatment resistance in brain tumors: status and controversies. Neoplasia, 9, 88292 (2007)

76. Singh, S. K., C. Hawkins, I. D. Clarke, J. A. Squire, J. Bayani, T. Hide, R. M. Henkelman, M. D. Cusimano \& P. B. Dirks: Identification of human brain tumour initiating cells. Nature, 432, 396-401 (2004)

77. Dalerba, P., S. J. Dylla, I. K. Park, R. Liu, X. Wang, R. W. Cho, T. Hoey, A. Gurney, E. H. Huang, D. M. Simeone, A. A. Shelton, G. Parmiani, C. Castelli \& M. F. Clarke: Phenotypic characterization of human colorectal cancer stem cells. Proc Natl Acad Sci U S A, 104, 10158-63 (2007)

78. O'Brien, C. A., A. Pollett, S. Gallinger \& J. E. Dick: A human colon cancer cell capable of initiating tumour growth in immunodeficient mice. Nature, 445, 106-10 (2007)

79. Tirino, V., V. Desiderio, R. d'Aquino, F. De Francesco, G. Pirozzi, U. Galderisi, C. Cavaliere, A. De Rosa \& G. Papaccio: Detection and characterization of CD133+ cancer stem cells in human solid tumours. PLoS ONE, 3, e3469 (2008)

80. Lee, C. J., C. Li \& D. M. Simeone: Human pancreatic cancer stem cells: implications for how we treat pancreatic cancer. Transl Oncol, 1, 14-8 (2008)

81. Collins, A. T., P. A. Berry, C. Hyde, M. J. Stower \& N. J. Maitland: Prospective identification of tumorigenic prostate cancer stem cells. Cancer Res, 65, 10946-51 (2005)

Abbreviation: CSC: cancer stem cell; AML: acute myeloid leukemia; SCID: severe combined immunedeficient; pCSCs: precancerous stem cell; VEGF: Vascular endothelial growth factor; SCLGC: stem cell-like glioma cells; GSC: germ-line stem cells; BM: basement membrane; ECM: extracellular matix; CAF: cancerassociated fibroblasts; MMPs: matrix metalloproteinases; TAM: tumor-associated macrophages; HIF: hypoxiainduced transcription factors. HGF: hepatocyte growth factor; IL-8: interleukin 8; LRP: lipoprotein receptorrelated protein; GSK3beta: glycogen synthase kinase-3beta; CK1: casein kinase 1; APC: adenomatous polyposis coli; HSCs: hematopoietic stem cells; CML: chronic myeloid leukemia; NECD: notch extracellular domain; NICD: notch intracellular domain; Mam: Mastermind; CNS: central nervous system; T-ALL: T-cell acute lymphoblastic leukemias; SMO: smoothened protein; BMP: bone morphogenic protein; GBM: glioblastoma

Key Words: Cancer Stem Cell, Niche, Pathway, Tumor Metastasis, Tumor Angiogenesis, Review

Send correspondence to: Daotai Nie, Department of Medical Microbiology, Immunology, and Cell Biology, Southern Illinois University School of Medicine, PO Box 


\section{Cancer stem cell and niche}

19626, Springfield, IL 62794-9626, USA, Tel: 217-545-

9702, Fax: 217-545-3227, E-mail: dnie@siumed.edu

http://www. bioscience.org/current/volS2.htm 